\title{
The Influence of the Clay Particles on the Mechanical Properties and Fracture Behavior of PLA/o-MMT Composite Films
}

\author{
E. Franco-Urquiza*, J. C. Velazquez-Infante, J. Cailloux, O. O. Santana, M. L1. \\ Maspoch
}

Centre Català del Plàstic, Universitat Politècnica de Catalunya. Edifici Vapor

Universitari de Terrassa, carrer Colom 114, Terrassa, Spain, 08222.

\begin{abstract}
In this study the influence of the morphology in the polylactic acid/Cloisite30B (PLA/C30B) composites on the mechanical and fracture behavior of calendered films was evaluated. An image analysis was performed using TEM micrographs in order to complete the morphological study. The micrographs were taken from ultramicrotomic samples corresponding to the melting flow (MD) and transverse direction (TD) of the films. The image analysis showed intercalated particles and tactoids, which was in accordance to the wide angle X-ray scattering (WAXS) patterns. TEM micrographs also revealed highly oriented particles. Uniaxial tensile tests were performed in the MD and TD directions finding a slight anisotropy of the films, which was associated to low level of chains orientation due to the calander processing. The fracture behavior was also evaluated in the MD and TD directions using deeply double-edge-notched (DDENT) specimens. The mechanical and fracture tests were evaluated on aging (brittle) and deaging (ductile) films. For ductile PLA/C30B composites, the reinforcement effect promoted by the clay particles was not evident.
\end{abstract}

\section{Introduction}

Polylactic acid (PLA) is a biodegradable polymer widely used in the past for medical applications. Nowadays, PLA has tremendous potential as an industrial commodity because of its attributes of biodegradability. This biopolymer is a linear aliphatic thermoplastic polyester and is produced from renewable resources via ring-opening polymerization of lactides.[1,2]

Commercial grades of PLA show similar attributes as polystyrene or polyethylene terephthalate and are considered to be a great alternative for the packaging sector, especially for bottles and disposable food containers.[2] This is the reason why the development of films made of PLA, along with their low environmental impact, has generated high expectations. Nevertheless, the performance of PLA is limited by its own brittle nature and mechanical properties.

One potential solution to improve its mechanical properties is the addition of nanosized particles. Montmorillonite (MMT) clay, which consists of platelets with an inner octahedral sandwiched two silicate tetrahedral layers,[3-5] is frequently used as a filler to produce polymer-layered silicates (PLS). However, raw MMT clay often produces immiscible phases; hence, the ammonium ions are exchanged by more voluminous organic cations to form organo-montmorillonite (o-MMT) clay. The ammonium ions 
increase both the clay galleries and the chemical compatibility between the hydrophilic clay surface and the organophilic polymer chains.

The most common reason for adding o-MMT into a polymer matrix is to increase its stiffness and strength.[5-7] Well-dispersed and well-aligned clay platelets are effective in improving the elastic modulus; meanwhile, adequate molecular compatibility (chemical bonding) is the key to enhancing the adhesion between filler and matrix, increasing the strength of the composite.

PLS can be formed using different processing techniques such as in situ polymerization or melt extrusion.[8-11] The latter is the most economical and flexible approach, because it involves compounding facilities used in commercial practice.

After compounding, an important issue is the mechanical performance of the PLS concerning the morphology of the clay particles in the matrix.[11, 12] PLS, also known as polymer nanocomposites, are often categorized into four types based on the degree of exfoliation and dispersion: conventional miscible composites, where tactoids (aggregated states) exist; intercalated composites, where polymer chains are inserted into the galleries; partially intercalated composites, where some exfoliated and intercalated clusters are randomly distributed into the matrix; and exfoliated composites, where individual layers of $\sim 1 \mathrm{~nm}$ thickness are totally dispersed into the matrix.

In recent years, several studies about PLA nanocomposites have been published.[5, 1316] However, to our knowledge, there are a few works dealing with the mechanical properties but not with the fracture behavior in a film form.

The goal of this work was to prepare and characterize films of PLA with low amounts of o-MMT clay to relate the platelets' morphology with the mechanical properties and fracture behavior by applying the essential work of fracture (EWF) approach. For this, an extensive particle analysis was performed and also used to predict the elastic modulus based on the composite theory.

Oftentimes, polymer nanocomposites are considered anisotropic materials; hence, in this work the PLA composite films are evaluated in both the melt (MD) and transverse (TD) directions.

\section{Experimental}

\section{MATERIALS}

Two commercial grades of PLA from NatureWorks LLC (Blair, Nebraska, USA) were used in this work: PLA2002D (PLA96) and PLA4032D (PLA98), with 95.8\% and 98\% 1-lactic acid enantiomer content, respectively. The flow index values were $7.0 \mathrm{~g} / 10 \mathrm{~min}$ for both resins. According to the supplier, the Young modulus for both matrices is approximately 3.5 GPa. Cloisite 30B from Southern Clay Products (Gonzales, TX, USA) is the o-MMT clay used as the filler. Colisite $30 \mathrm{~B}$ is organically modified with methyl tallow bis-2-hydroxyethyl quaternary ammonium chloride (MT2EtOH) with a cation exchange capacity of $90 \mathrm{meq}$ per $100 \mathrm{~g}$, a density of $1.98 \mathrm{~g} / \mathrm{cm}[\underline{3}]$, and a weight loss on ignition of $30 \%$. The particle sizes are $90 \%<13 \mu \mathrm{m}, 50 \%<6 \mu \mathrm{m}$, and $10 \%<$ 
$2 \mu \mathrm{m}$, and the galleries have a $d$ spacing $\left(d_{(001)}\right)$ of $18.5 \AA\left(2 \theta=4.8^{\circ}\right)$. The o-MMT was used as received.

\section{COMPOSITE AND FILM PREPARATION}

PLA composite films were prepared in a three-step melt-extrusion process using a corotating twin-screw extruder (Collin ZK 25, Ebersberg, Germany) with a screw diameter of $25 \mathrm{~mm}$ and an $L / D$ ratio of 36 . The twin-screw rotation speed was set at 85 rpm with barrel temperatures between $145^{\circ} \mathrm{C}$ in the feed section and $200^{\circ} \mathrm{C}$ in the extrusion die. PLA pellets were dried at $80^{\circ} \mathrm{C}$ for $3 \mathrm{~h}$ in a dehumidifier (Piovan DSN506HE, Maria di Sala (Venice), Italy) prior to each melt-extrusion step. Similarly, $\mathrm{C} 30 \mathrm{~B}$ was vacuum dried under the same conditions $\left(80^{\circ} \mathrm{C}\right.$ for $\left.3 \mathrm{~h}\right)$ in a desiccator.

A masterbatch with a nominal filler content of $10 \mathrm{wt} \%$ was compounded in the first step of the melt-extrusion process. The masterbatch was homogenized in the second step. Finally, the third step was used to mix the masterbatch with neat PLA to obtain composites with nominal compositions of 0.5 and $2.5 \mathrm{wt} \%$ (PLA/ 0.5 and PLA/2.5C30B respectively). For this last extrusion step, the circular extrusion die used for the compounding (first and second steps) was replaced with a flat extrusion die to obtain the films, which were then calendered using a calender machine (Collin Teach Line (Ebersberg, Germany) with CR72-T chill rolls at $50^{\circ} \mathrm{C}$ ) placed at the end of the extruder to obtain homogeneous films approximately $400 \mu \mathrm{m}$ in thickness and $100 \mathrm{~mm}$ in width. The chill rolls' speed was set to avoid the polymer chain orientation induced by processing as much as possible.

The amount of MMT of the composite films was determined following the ISO 3451-1 plastics test standard (determination of ash, part 1) using a muffle furnace (Selecta ${ }^{\circledR}$ 367 PE, JP Selecta S.A., Abrera, Barcelona, Spain) at $600^{\circ} \mathrm{C}$ until constant weight was achieved. The results are summarized in Table $\underline{I}$.

Table I. Clay Content, MFI and WAXS Data for Neat PLA, Unfilled PLA Films, and PLA Composite Films

\begin{tabular}{|c|c|c|c|c|c|c|c|c|}
\hline Material & $\begin{array}{l}\text { wt. \% } \\
\text { MMT* }\end{array}$ & $\begin{array}{c}\text { MFI } \\
\text { (g/10 min) }\end{array}$ & & $2 \theta(\stackrel{\circ}{)}$ & \multicolumn{4}{|c|}{$\begin{array}{c}\mathrm{d} \\
(\mathrm{nm})\end{array}$} \\
\hline PLA96 & --- & $7 \pm 0.8$ & & & & & & \\
\hline PLA98 & --- & $7.4 \pm 0.6$ & & & & & & \\
\hline PLA96 film & --- & $10 \pm 1.1$ & & & & & & \\
\hline PLA98 film & --- & $9.7 \pm 0.8$ & & & & & & \\
\hline $\mathrm{C} 30 \mathrm{~B}$ & --- & & 5.0 & --- & --- & 1.8 & --- & --- \\
\hline
\end{tabular}




\begin{tabular}{lcccccccc} 
PLA96/0.5C film & 0.4 & $9.9 \pm 1.2$ & 2.8 & 5.5 & 7.7 & 3.2 & 1.6 & 1.1 \\
PLA96/2.5C film & 1.7 & $14.1 \pm 0.9$ & 2.8 & 5.7 & --- & 3.2 & 1.6 & --- \\
PLA98/0.5C film & 0.3 & $11 \pm 0.8$ & 2.9 & 6.0 & --- & 3.0 & 1.5 & --- \\
PLA98/2.5C film & 1.7 & $15.5 \pm 1.4$ & 2.4 & 6.1 & --- & 3.7 & 1.4 & --- \\
\hline
\end{tabular}

\section{MELT FLOW INDEX}

The melt flow index (MFI) is an assessment of average molecular mass, which is an inverse measure of the melt viscosity of polymers. Therefore, the larger the MFI value the lower the viscosity and, therefore, the average molecular weight of the polymer is reduced.

Knowing the MFI of a polymer is vital in anticipating and controlling its processing. In this work, the MFI was determined for neat PLA, unfilled PLA films, and PLA composite films using a CEAST 684 MFI tester (Cerdanyola, Barcelona, Spain) (load $2.16 \mathrm{~kg}$, temperature $210^{\circ} \mathrm{C}$, according to the ASTM D-1238 standard).

The unfilled PLA films were obtained through the same composite film processing conditions, which included the three-step melt-extrusion process (using the twin-screw extruder) and the chill-rolls calender in the last extrusion step. Neat twice-processed PLA was used as the masterbatch and was diluted at 0.5 and $2.5 \mathrm{wt} \%$ with nonprocessed neat PLA during the third extrusion step to simulate the composite film processing.

\section{MORPHOLOGICAL CHARACTERIZATION}

Relating the mechanical performance of the polymer composite to the o-MMT morphology is an important issue to be considered.

Wide angle X-ray scattering (WAXS) and transmission electron microscopy (TEM) are so far the most common and useful characterization techniques for polymer nanocomposites. WAXS is relatively simple to carry out and allows determination of the platelet separation ( $d$ spacing), which is required to categorize polymer nanocomposites. However, many factors must be considered before stating if the composite is a conventional miscible, intercalated, or exfoliated composite.[5, 17] TEM observation is a far more direct way of visualizing composite morphology. The observation is simple, but the specimen preparation requires considerable skill and patience. Despite TEM allowing actual visualization of the particles' morphology, which is obviously relevant in performing the counting and analysis of the clay particles, this approach is criticized because it reveals the morphology in just a very small region. So, it is highly recommended to take samples from different locations and directions.

In this work, the WAXS patterns were performed in the lateral zone of the films. The diffraction was run in a Siemens D5000D diffractometer (Munich, Germany) at room 
temperature $\left(\sim 23^{\circ} \mathrm{C}\right)$, with a filtered $\mathrm{Cu} \mathrm{K} \alpha$ radiation and a wavelength of $1.542 \AA$. The diffraction angle was scanned in the range of $2 \theta=2-10^{\circ}$ with a scan speed of $2^{\circ} \mathrm{min}^{-1}$ and step size of $0.05^{\circ}$. The tube voltage and filament current were set to $40 \mathrm{kV}$ and 30 $\mathrm{mA}$, respectively. Bragg's law $(\lambda=2 d \sin \theta)$ was applied to calculate the corresponding $d$ spacing of the clay $(d)$.

Several small samples were randomly taken along the films in the MD and TD directions, as shown schematically in Fig. 1. The samples were embedded in Spurr resin and then ultra-sectioned ( $<100 \mathrm{~nm}$ in thickness) using a diamond knife holder in a 701701 Reichert-Jung ultracutter (Depew, NY, USA). The ultrathin sections were deposited on 400-mesh TEM copper grids and then captured with a Hitachi 800MT microscope (Krefeld, Germany) operating at $300 \mathrm{kV}$.

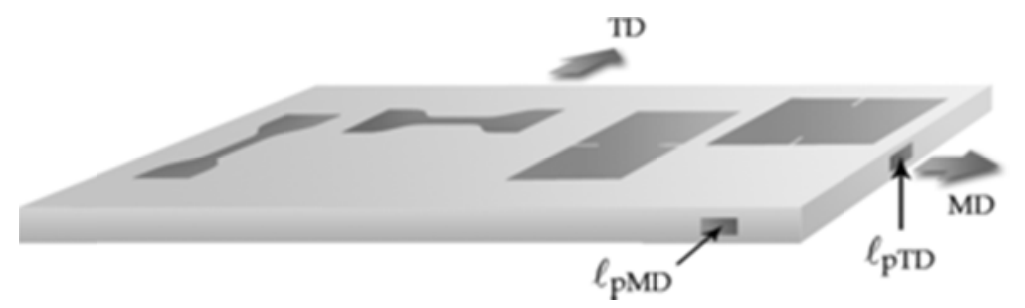

Figure 1.-Schematic representation of the PLA composite film, in which tensile and fracture specimens as well as TEM samples are depicted.

Image analysis is often used to quantify the distribution of the clay particles into the polymer matrix in an attempt to complete the morphological characterization of the composite. In this work, high-contrast TEM micrographs from the ultrathin samples taken along the films were selected with an accuracy magnification, which allowed observation of a relatively large number of particles. The micrographs in TIFF format were transferred to a white background to identify and distinguish more clearly the single platelets and agglomerate particles from the typical gray color of the background in TEM micrographs. Subsequently, the micrographs were processed by standard image analysis software (ImageJ) to count and measure the particle dimensions. In this work, the term particle refers either to a single platelet or multiple platelets in a stack. Also, it is necessary to take into account that the ImageJ software considers the particles as elliptical shapes, where the major and minor axes are represented as the effective length and thickness $\left(\ell_{p}\right.$ and $\left.t_{p}\right)$, respectively.

\section{MECHANICAL PROPERTIES}

Uniaxial tensile tests (ASTM D-638 standard) were carried out on dumbbell-shaped specimens in a universal testing machine (Galdabini Sun 2500, Cardano Al Campo, Varese, Italy) equipped with a $5-\mathrm{kN}$ load cell. The tensile specimens were machined from the lateral zone of the films in the MD and TD directions, as shown schematically in Fig. 1. The tests were performed at a crosshead rate of $10 \mathrm{~mm} / \mathrm{min}$ and at room temperature $\left(23 \pm 2{ }^{\circ} \mathrm{C}\right)$. Young's modulus $(E)$ and yield strength $\left(\sigma_{y}\right)$ were obtained from the engineering stress versus strain curves, and the elastic deformation was measured using a video extensometer (Mintron OS-65D, Fremont, CA, USA).

Theoretical modeling is an appealing approach to the design of effective polymer nanocomposites. Using composite theory, $[12,18]$ it is possible to predict the 
performance of polymer composites relating the individual contribution of the component properties such as matrix and filler stiffness, volume fraction, aspect ratio, and filler orientation. J. C. Halpin[18] developed the theory to predict the stiffness of anisotropic composites as a function of a filler aspect ratio. The Halpin-Tsai equation can be adapted for a variety of filler geometries such as cylindrical fibers or rectangular lamellae (similar to the silicate particles). By applying this theory, the longitudinal (E11) and transverse (E22) moduli are expressed in the following general form:

$\frac{E}{E_{m i}}=\frac{1+\zeta \eta \phi_{f}}{1-\eta \phi_{f}}$

where $E$ and $E_{m}$ are the elastic modulus of the composite and matrix, respectively, $\zeta$ is the shape factor that depends on the filler geometry and loading direction, $\phi_{f}$ is the filler volume fraction, and $\eta$ is given by the following expression:

$\eta=\frac{E_{f} / E_{m z}-1}{E_{f} / E_{m}+\zeta}$

where $E_{f}$ is the elastic modulus of the MMT clay particles ( 178 GPa).[12]

\section{FRACTURE BEHAVIOR}

The fracture behavior of PLA composite films was characterized using the EWF approach.[19-22] The EWF is based on the partition of the total energy $\left(W_{f}\right)$ consumed during the postyielding fracture of a precracked specimen where two distinct zones can be observed. The inner or process zone is related to the fracture process where the EWF $\left(W_{e}\right)$, which is associated with $W_{f}$, is proportional to the ligament section $(\ell)$. The outer or plastic zone involves the non-EWF or plastic work $\left(W_{p}\right)$, where dissipative processes occur.[23] The work consumed in the outer zone is proportional to the volume of the deformed region. Further and very detailed explanation of the EWF methodology applied to polymer composite films can be found in previous studies.[6, 7, 24, 25]

In this work, deeply double-edge-notched tension (DDENT) specimens in the MD and TD directions (Fig. 1) were tested in tension loading under the same conditions used for the tensile tests ( $5 \mathrm{kN}$ load cell, $10 \mathrm{~mm} / \mathrm{min}$ crosshead speed, and room temperature). Specimens with dimensions of $90 \mathrm{~mm}$ overall length, $60 \mathrm{~mm}$ width, and $\ell$ between 5 and $20 \mathrm{~mm}$ were prepared. A fresh razor blade was used to sharpen the notches prior to the testing. Although the EWF method has been proven to be sensitive to notch quality,[26] it was assumed that the damage at the notch tip would be the same in all specimens.

After testing, the ligament length was measured using a profile projector Starrett Sigma VB300 (Athol, MA, USA), and the fracture surfaces from the DDENT specimens (corresponding to $\ell \sim 15 \mathrm{~mm}$ ) were observed in a scanning electron microscope (SEM) JEOL JSM 6400 (Peabody, MA, USA).

The mechanical properties as well as the fracture behavior were evaluated on specimens machined directly from the films with and without thermal treatment. The treatment consisted in applying heat $\left(60^{\circ} \mathrm{C}\right)$ during 20 min and quenching using cold water and 
ice. The heating above the glass transition temperature of the PLA promotes an increase in the free volume due to the high mobility of the polymer chains; meanwhile, the quenching favors that this free volume is maintained for a period of time. Further information about this thermal treatment can be found in a previous work.[24]

\section{Results and Discussion}

\section{MFI AND MORPHOLOGY}

MFI was determined for neat PLA, unfilled PLA films, and PLA composite films. The results are presented in Table $\underline{\mathrm{I}}$.

The unfilled PLA films were prepared through three-step twin-screw extrusion and cast film to compare the effect of the compounding process.

From the results, it is evident that the MFI increases when PLA is processed via meltextrusion and cast film, which could be associated with a significant level of molecular degradation. It is well known that PLA polymers are very sensitive to temperature; hence, degradation of the unfilled PLA films may occur during the extrusion process.

With respect to the PLA composite films, the higher the filler content the higher the MFI. The clay seems acting as a plasticizer, promoting the reduction of the MFI. Other factors such as shear stress (which is higher when the clay content increases) and hydrolysis reactions caused by the presence of water in the galleries could promote a higher level of degradation in the PLA composite films with respect to the unfilled PLA films.[2] ]

Table I also lists the values of $2 \theta$ and clay $d$ spacing obtained from the WAXS spectra (Fig. 2) corresponding to the Cloisite 30B and the PLA composite films.
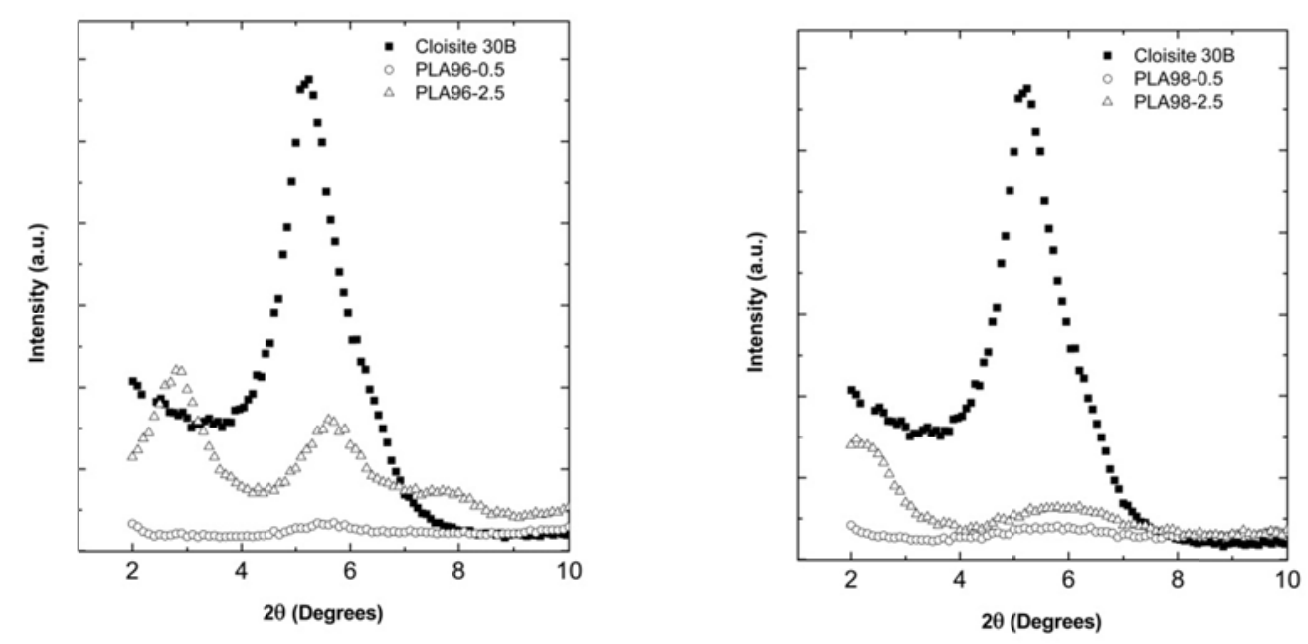

Figure 2. WAXS patterns for the filler and the composite films: (a) Cloisite 30B and PLA 96 composites and (b) Cloisite $30 \mathrm{~b}$ and PLA 98 composites. 
The pattern of the filler reveals a single broad, intense peak at around $2 \theta=5^{\circ}(d \sim 1.8$ $\mathrm{nm}$ ), which is characteristic of the basal spacing of the Cloisite $30 \mathrm{~B}$. The patterns corresponding to the PLA composite films show several diffraction peaks located at different positions, and they are less intense than the one from the filler.

It is well documented that the presence of multiple diffraction pealks points to the development of distinct structures such as intercalation, where laminates are separated by the presence of polymer chains, or tactoids, where clay particles remain as a stack.

The diffraction peaks located at angles lower than that of the Cloisite 30B should represent the intercalation of polymer chains in the clay galleries, which represents larger $d$ spacing (Table $\mathrm{I}$ ). The displacement of the diffraction peaks at higher angles could be attributed to the loss of unbound surfactant or to surfactant degradation.

The patterns corresponding to the PLA composite films with low filler content $(0.5$ $\mathrm{wt} \%$ ) seem to reveal exfoliated structures because of the relative absence of the basal peak. However, the absence of diffraction peaks does not always indiciate the existence of single laminates randomly distributed into the polymer matrix. As stated in many studies, $[6,28]$ when tactoids are internally disordered or not well aligned to one another, the peak intensity will be low and may appear to be completely absent.

TEM observation is commonly used to verify WAXS measurements. Figure $\underline{3}$ shows representative TEM micrographs corresponding to ultrathin samples taken from the PLA composite films with a nominal clay content of $2.5 \mathrm{wt} \%$ in the MD and TD directions (see Fig. 1).

a)

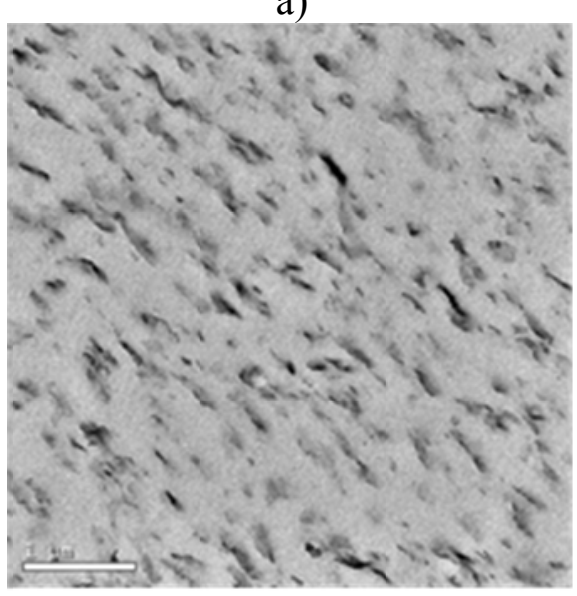

c) b)

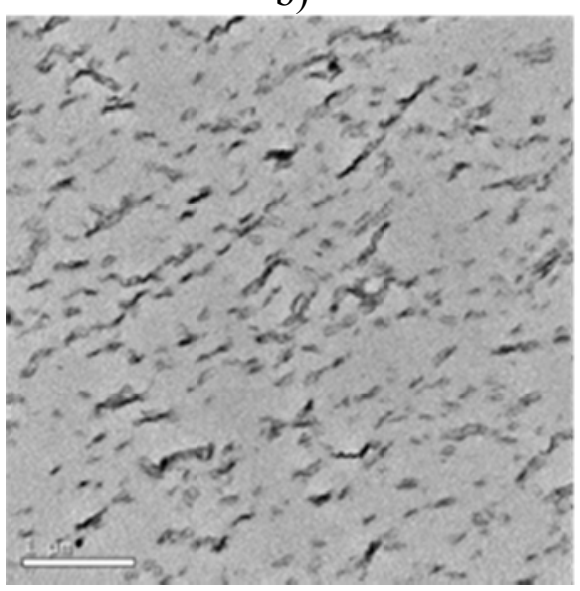

d) 

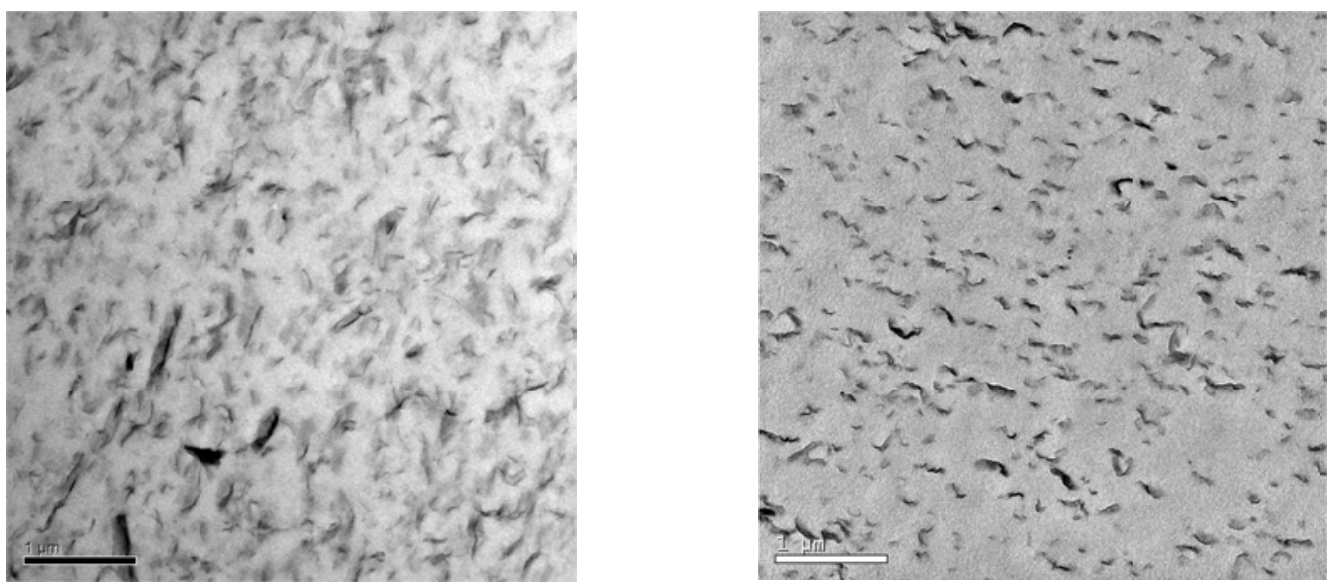

Figure 3. TEM micrographs that show the clay particle distribution corresponding to (a) PLA96/2.5C30B in MD, (b) PLA96/2.5C30B in TD, (c) PLA98/2.5C30B in MD, and (d) PLA98/2.5C30B in TD.

TEM micrographs revealed a homogeneous distribution of the clay particles with some intercalation grade and tactoids irrespective of the clay content, which was expected according to the previously analyzed WAXS patterns. Furthermore, the clay particles exhibited high degrees of orientation in both directions.

Higher magnifications (Fig. 4) revealed distorted clay particles, which could be associated with both nonoptimum shearing of platelet stacks and low diffusion during peel apart, because of possible surfactant degradation during the twin-screw extrusion processing. $[6,17]$ In spite of the extrusion process presenting several industrial advantages, it is well known that to achieve a satisfactory degree of exfoliation it is necessary to take into account several factors such as temperature, pressure, melt viscosity, or even screw design. All of these factors are able to influence the morphology of the clay platelets and the degree of exfoliation on PLA composite films.

a)

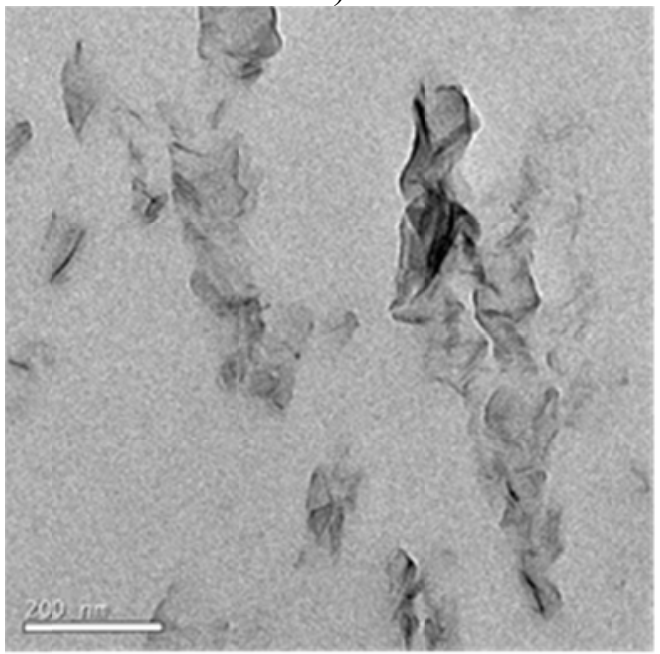

c) b)

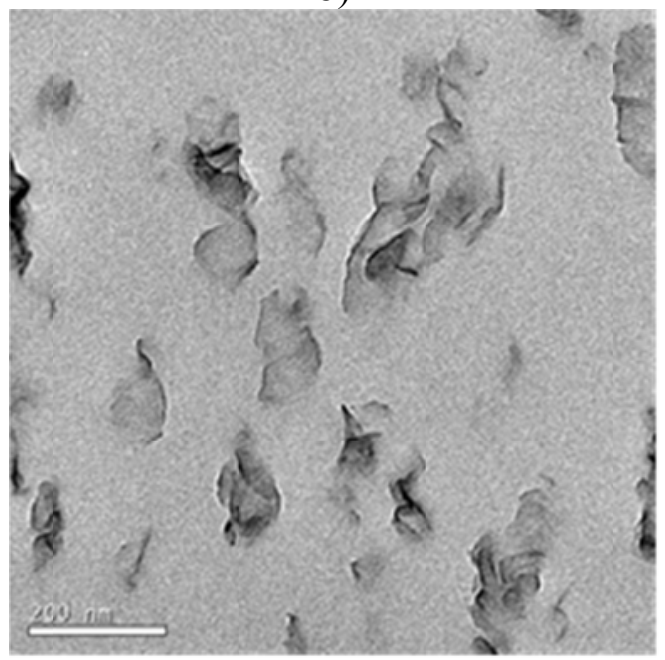

d) 

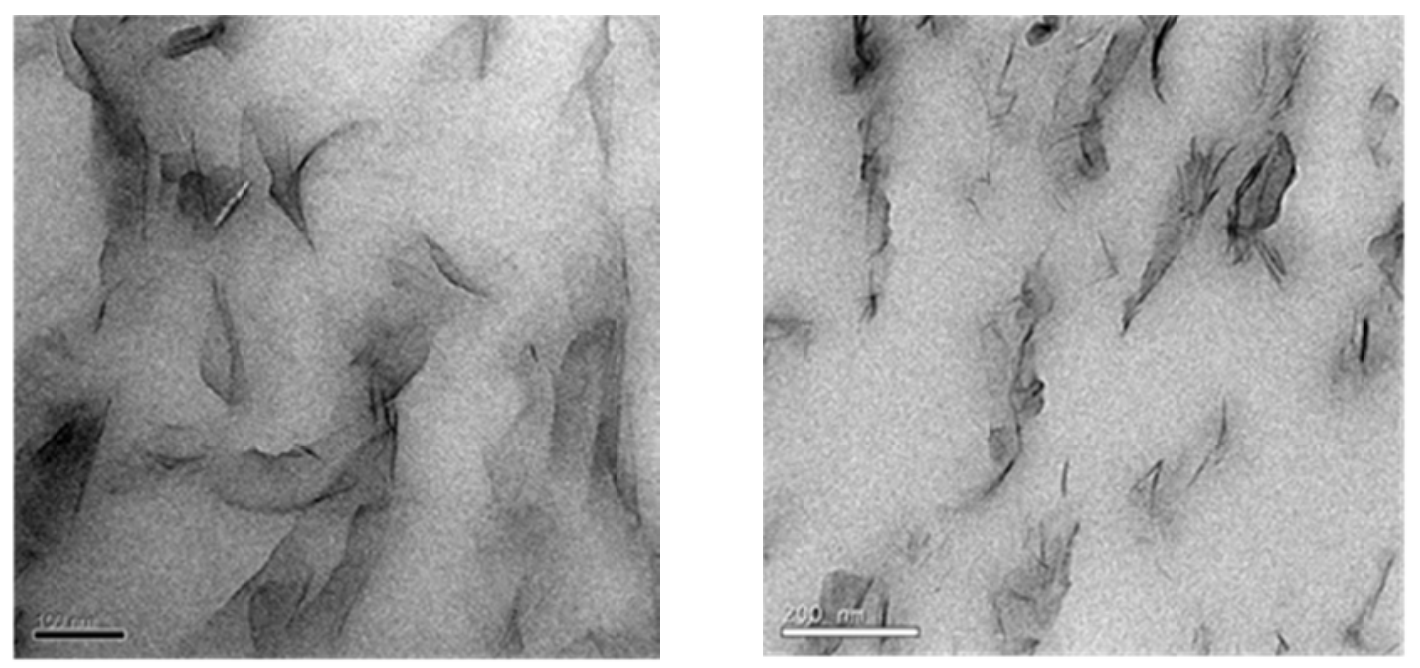

Figure 4.-TEM micrographs at higher magnifications corresponding to the (a) PLA96/2.5C30B in MD, (b)PLA96/2.5C30B in TD, (c) PLA98/2.5C30B in MD, and (d) PLA98/2.5C30B in TD.

\section{IMAGE ANALYSIS}

It is very useful to perform image analysis for counting and sizing the clay particles from representative TEM micrographs to complete, in a quantitative manner, the morphological study of the PLS. Typically, the clay particles are assumed to have a disk-like shape, with a high aspect ratio and large surface areas. Quantitative assessments such as the number of particles, the effective particle length, and thickness ( $\ell_{p}$ and $t_{p}$, respectively) and the aspect ratio $\left(\ell_{p} / t_{p}\right)$ are summarized in Table $\underline{\mathrm{II}}$.

Table II. Data from the Clay Particles Analysis of the PLA Composite Films in the MD and TD Directions

\begin{tabular}{|c|c|c|c|c|c|c|c|}
\hline Material & $\begin{array}{l}\text { Location of } \\
\text { TEM } \\
\text { micrographs }\end{array}$ & $\begin{array}{l}\text { Total } \\
\text { number } \\
\text { of } \\
\text { partilces }\end{array}$ & $\begin{array}{c}\ell_{\mathrm{p}} \\
(\mathrm{nm})\end{array}$ & $\begin{array}{c}t_{p} \\
(n m)\end{array}$ & $\begin{array}{l}\text { Average } \\
\text { number of } \\
\text { platelets } \\
\text { per particle } \\
\text { (n) }\end{array}$ & $\begin{array}{c}\text { Aspect } \\
\text { ratio } \\
\left(\ell_{\mathrm{p}} / \mathrm{t}_{\mathrm{p}}\right)\end{array}$ & $\begin{array}{c}\left(\ell_{\mathrm{pTD}}\right. \\
\left./ \ell_{\mathrm{pMD}}\right)\end{array}$ \\
\hline \multirow[t]{2}{*}{ PLA96/0.5C30B } & $\mathrm{TD}$ & 188 & 140 & 7 & 4 & 20 & 1.6 \\
\hline & MD & 274 & 88 & 9 & 5 & 9 & \\
\hline \multirow[t]{2}{*}{ PLA96/2.5C30B } & TD & 756 & 82 & 6 & 4 & 14 & 1 \\
\hline & MD & 468 & 82 & 6 & 4 & 14 & \\
\hline \multirow[t]{2}{*}{ PLA98/0.5C30B } & TD & 189 & 69 & 4 & 3 & 20 & 0.6 \\
\hline & MD & 278 & 108 & 5 & 4 & 22 & \\
\hline
\end{tabular}




$\begin{array}{lrrrrrrr}\text { PLA98/2.5C30B } & \text { TD } & 583 & 124 & 7 & 3 & 14 & 1.2 \\ & \text { MD } & 401 & & & & \end{array}$

As expected, the number of clay particles increased with the clay content but this increase was not linear if the amount of MMT clay was considered (Table I). The counting of the number of clay particles varied between $23 \%$ and $14 \%$ for the PLA96/2.5C30B and the PLA98/2.5C30B in TD and MD, respectively, in spite of both composites having similar amounts of MMT. Therefore, the higher the clay content the greater the tendency to become agglomerated, being the PLA98 composite films more sensitive to the formation of tactoid structures.

The effective length of the clay particles $\left(\ell_{p}\right)$ seems to be inconclusive because it was not possible to appreciate an evident tendency in either the clay content or the grade of the PLA matrix. In a similar way, the thickness of the particles $\left(t_{p}\right)$ did not show any particular variation, and the data obtained for the aspect ratio $\left(\ell_{p} / t_{p}\right)$ were even lower than that reported by other authors.[12, 29]

The previous results seem to indicate that the mechanism for organoclay dispersion and exfoliation during the melt-extrusion process was not so effective when the PLA was mixed with o-MMT. It is well known that shear stress during the melt extrusion favors the breakup of large organoclay particles into dispersed stacks before individual platelets peel apart, which happens after delamination of the layered stacks.[30] The values of $\ell_{p}$ and $\ell_{p} / t_{p}$ presented in this work (Table $\underline{\text { II }}$ ) suggest that breakup of silicate tactoids as well as some diffusion of polymer chains between sandwiched platelets occur with an inefficient delamination process and poor exfoliation. The previous results could be attributed to a low shear level promoted by the reduction in the PLA viscosity when adding clay particles during the melt-extrusion process, according to the MFI values presented in Table I. Notwithstanding this, homogeneous dispersion of the clay particles was found in the PLA composite films, as revealed by the TEM micrographs in Fig. $\underline{3}$.

By relating $\ell_{p}$ in the MD and the TD directions, it is possible to note that $\ell_{p \mathrm{TD}} / 1_{p \mathrm{MD}}$ results in values close to 1 (Table $\underline{\text { II }}$ ), which gives an idea about the exfoliation process and the isotropic level in the PLA composite films. The similar values of $\ell_{p}$ obtained in both directions should be indicative of the three-step extrusion process that has not been so effective in skewing the platelet stacks and creating larger effective length particles.

In addition, it is very important to take into account that the image J software estimates the clay particles' dimensions as elliptical shapes; hence, the image analysis results are highly complicated for composites where the clay particles are not perfectly aligned or when the high exfoliation is not well developed. In addition, when manipulating the TEM micrographs some pixels are bleared or even deleted, wherewith the finest and the smallest particles could be not considered. Therefore, the image analysis becomes trustworthy for composites with laminate morphology (i.e., highly exfoliated and oriented laminates). Otherwise, the image analysis must be used as a general tendency that it allows complementing the composite morphologies without being conclusive. In our case, where the clay particles are oriented but not laminated (Fig. 4 ), the results 
provided by the image analyses were used as a supplement to our understanding of the mechanical and fracture behavior of the PLA composite films.

\section{MECHANICAL PROPERTIES}

Halpin-Tsai theory was applied to predict the Young modulus of the PLA composite films. This model requires two main parameters: the average aspect ratio $\left(\ell p / t_{p}=16\right)$ and the number of platelets per particle $(n)$, which was between 3.1 and 4.6 platelets per stack according to manual counting using higher magnifications of TEM micrographs. Therefore, $n$ was considered to be 3.8 as the average result for all PLA composite films and was used to predict the modulus.

Figure $\underline{5}$ shows the effect of the number of platelets per particle and the MMT volume fraction $\left(\phi_{M M}\right)$ on the elastic moduli determined by the Halpin-Tsai theory. The straight lines in the plot are related to the theoretical prediction and the characters point to the experimental values.

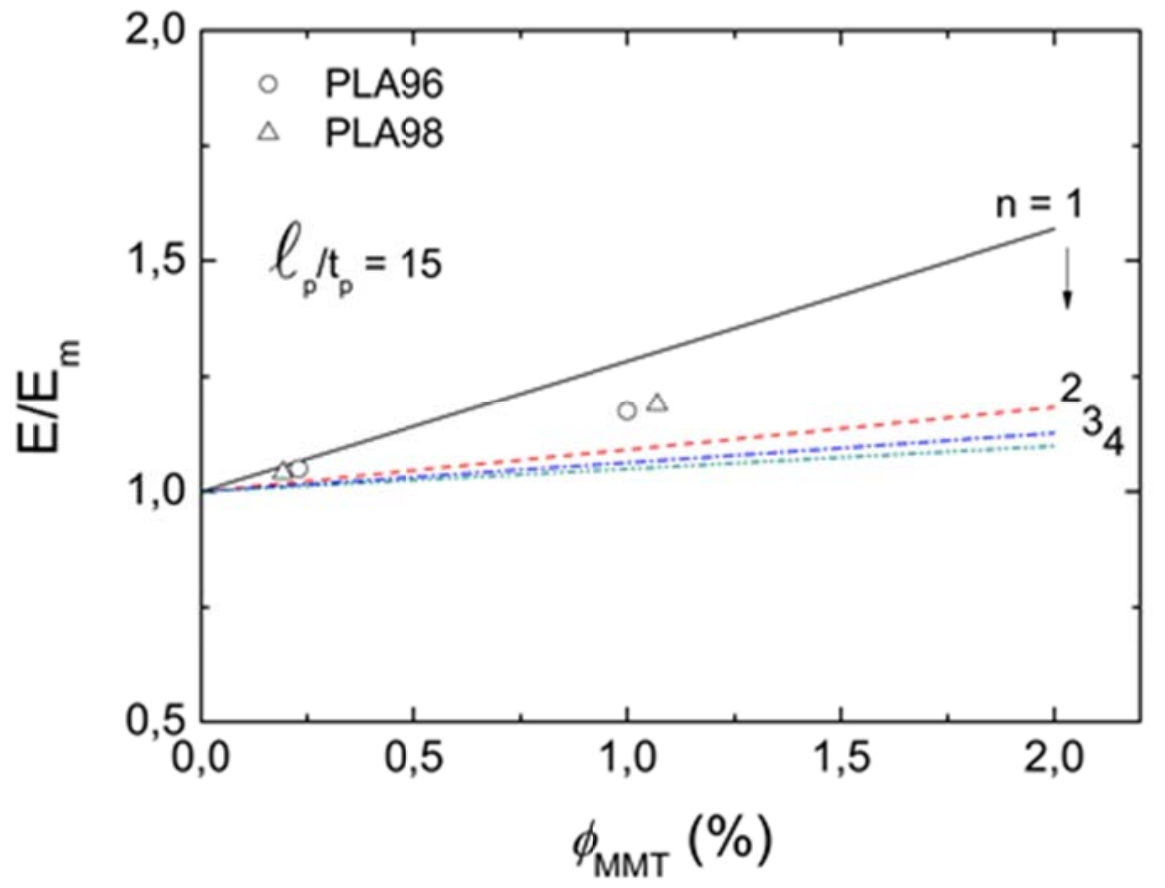

Figure 5.- Experimental (characters) and theoretical (dashed lines) moduli relating to the MMT volume fraction. According to the theoretical prediction, when $n=1$ the $E / E_{m}$ relationship increases notoriously as the volume fraction because a high degree of exfoliation exists. However, tactoid structures $(n>1)$ promote a dramatic reduction in the $E / E_{m}$, with insignificant variations as $\phi_{\text {мm }}$ increases. Therefore, the higher the number of platelets per stack the lower the values for the stiffness.

With reference to the experimental results, the clay particles seem to improve the stiffness of the PLA in spite of the resulting matrix being very sensitive to the compounding process. 
When relating the experimental values with the theoretical predictions, it is possible to observe that the experimental data are not well adjusted to the Halpin-Tsai model, as plotted in Fig. $\underline{5}$. This could be attributed to several factors such as the orientation of the polymer chains, the nature of the organomodifier, and the level of degradation of the polymer matrix that are not considered by the theory.

Table III shows the mechanical parameters obtained from the stress versus strain curves corresponding to the specimens machined from the MD and TD directions, as schematized in Fig. 1 .

Table III. Mechanical Parameters of the PLA Composite Films

\begin{tabular}{llllllll}
\hline \multicolumn{7}{c}{ Untreated Films } & \multicolumn{3}{c}{ Thermal-Treated Films } \\
Material & $\begin{array}{l}\text { Drawing } \\
\text { Direction }\end{array}$ & E (GPa) & $\begin{array}{l}\boldsymbol{\sigma}_{\mathbf{y}} \\
\mathbf{( M P a})\end{array}$ & $\boldsymbol{\varepsilon}_{\mathbf{b}} \mathbf{( \% )}$ & $\mathbf{E}(\mathbf{G P a})$ & $\left.\boldsymbol{\sigma}_{\mathbf{y}} \mathbf{( M P a}\right)$ & $\boldsymbol{\varepsilon}_{\mathbf{b}}(\mathbf{\%})$ \\
PLA96/0.5C & MD & $3.9 \pm 0.1$ & $74 \pm 2$ & $14 \pm 3$ & $3.6 \pm 0.2$ & $65 \pm 2$ & $385 \pm 8$ \\
PLA96/2.5C & & $4.2 \pm 0.2$ & $75 \pm 2$ & $22 \pm 4$ & $3.6 \pm 0.1$ & $65 \pm 1$ & $414 \pm 19$ \\
PLA96/0.5C & TD & $3.9 \pm 0.2$ & $66 \pm 4$ & $3 \pm 1$ & $3.6 \pm 0.1$ & $62 \pm 3$ & $411 \pm 38$ \\
PLA96/2.5C & & $4.3 \pm 0.3$ & $65 \pm 3$ & $4 \pm 1$ & $3.8 \pm 0.1$ & $63 \pm 2$ & $384 \pm 10$ \\
PLA98/0.5C & MD & $4.1 \pm 0.1$ & $72 \pm 3$ & $6 \pm 2$ & $3.4 \pm 0.2$ & $62 \pm 3$ & $386 \pm 16$ \\
PLA98/2.5C & & $4.4 \pm 0.2$ & $74 \pm 2$ & $12 \pm 3$ & $3.6 \pm 0.1$ & $62 \pm 3$ & $361 \pm 10$ \\
PLA98/0.5C & TD & $3.7 \pm 0.2$ & $62 \pm 3$ & $3 \pm 1$ & $3.5 \pm 0.1$ & $60 \pm 2$ & $308 \pm 28$ \\
PLA98/2.5C & & $4.3 \pm 0.3$ & $64 \pm 2$ & $7 \pm 2$ & $3.7 \pm 0.2$ & $61 \pm 3$ & $345 \pm 35$ \\
\hline
\end{tabular}

With respect to the filler content, no significant changes in the tensile strength were found by increasing the clay content, which suggests that in spite of a good interaction between the matrix and the filler probably existing, it is not good enough to improve the strength of the PLA composite films, at least not up to $2.5 \mathrm{wt} \%$ of clay. Furthermore, the tensile strength for the specimens tested in MD was a little bit higher than the specimens tested in the TD direction. According to the preceding sections, the $1_{p \mathrm{TD}} / 1_{p \mathrm{MD}}$ relationship was close to 1 ; hence, the results would be associated more with the induced polymer chain orientation in MD during the casting of the film than to the filler.[7]

An unexpected behavior on ductility was found because the elongation increased with the clay content, which seems to be associated with the plasticizing effect promoted by the organomodifier of the Cloisite 30B. This behavior was notably more evident in the MD than the TD direction, which could be attributed to the anisotropy caused by the orientation of the chains in MD.

With respect to the thermal treatment, it is possible to appreciate that the stiffness and strength of the PLA composite films are clearly lower if they are compared to the untreated films. The effect of the thermal treatment is to increase the free volume through the easy movement of the polymer chains, which allows greater displacement to 
be achieved with less energy. This is the main reason why the Young's modulus and tensile yield decrease even when the elongation increases dramatically with respect to the composite films without thermal treatment.
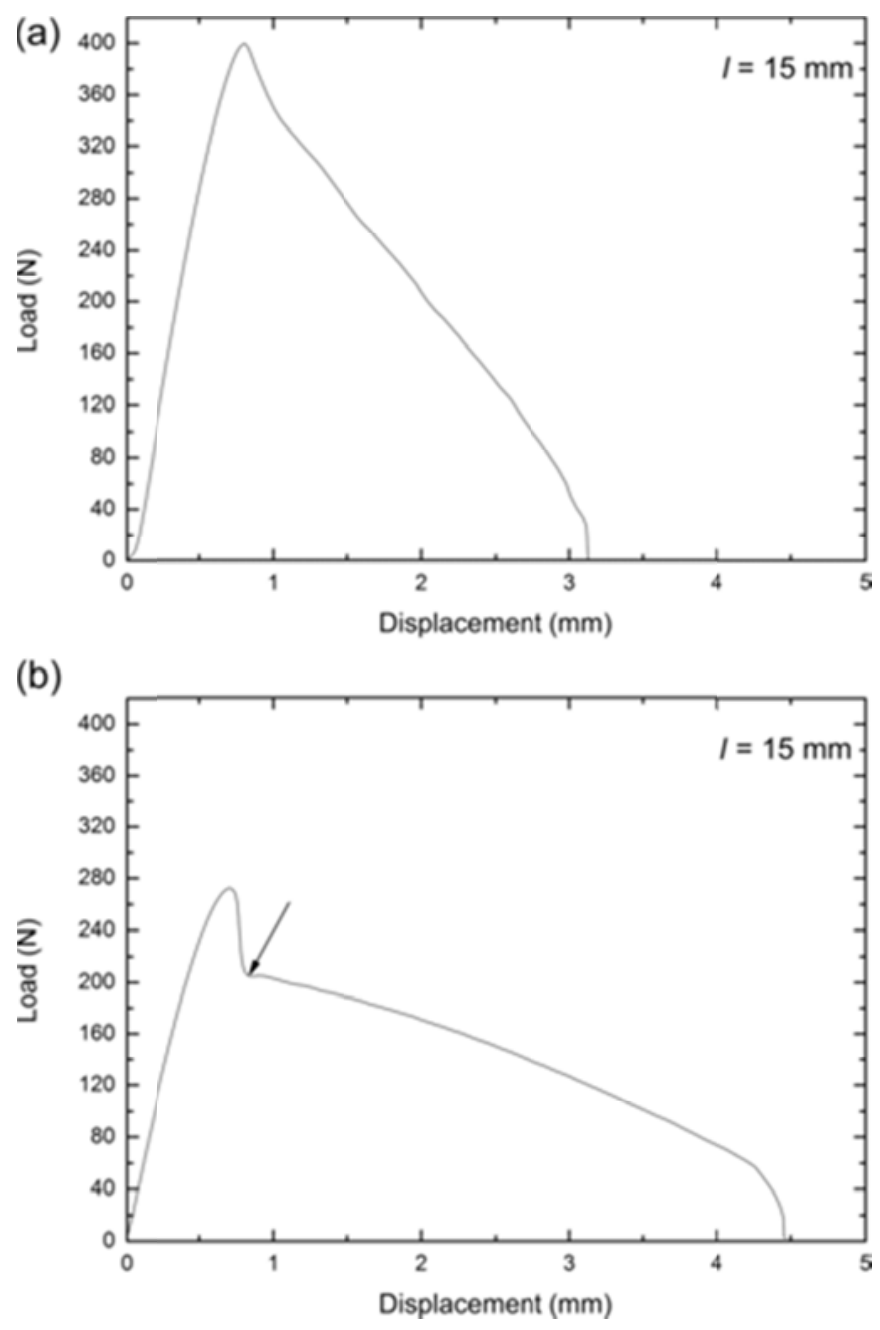

Figure 6.- Representative EWF curves corresponding to the PLA96/2.5C30B film with a nominal $l=15 \mathrm{~mm}$ for (a) untreated composite film and (b) thermal-treated composite film. The shape of the curves showed here was very similar to the PLA98 composite films. The arrow indicates the total yield before crack propagation.

The fracture parameters, determined by plotting the specific fracture energies $\left(w_{f}\right)$ as a function of ligament length $\ell$, are shown in Table IV. 
Table IV. Fracture Parameters of PLA Composite Films

\begin{tabular}{|c|c|c|c|c|c|c|c|c|c|}
\hline \multirow[b]{2}{*}{ Material } & & \multicolumn{3}{|c|}{ Untreated Films } & \multicolumn{5}{|c|}{ Thermal-Treated Films } \\
\hline & & $\begin{array}{l}\boldsymbol{w}_{e} \\
\left(\mathbf{k} \mathbf{J} / \mathbf{m}^{2}\right)\end{array}$ & $\begin{array}{l}\boldsymbol{\beta} \boldsymbol{w}_{p} \\
\left(\mathbf{M} \mathbf{J} / \mathbf{m}^{3}\right)\end{array}$ & $R^{2}$ & $\begin{array}{l}\boldsymbol{w}_{e} \\
\left(\mathbf{k J} / \mathbf{m}^{2}\right)\end{array}$ & $\begin{array}{l}\beta w_{p} \\
\left(\mathbf{M} \mathbf{J} / \mathbf{m}^{3}\right)\end{array}$ & $R^{2}$ & $\begin{array}{l}w_{p} \\
\left(\mathbf{M} \mathbf{J} / \mathbf{m}^{3}\right)\end{array}$ & $\boldsymbol{\beta}$ \\
\hline PLA96/0.5C30B & MD & 37 & 2.6 & 0.82 & 39 & 5.6 & 0.98 & 35 & 0.16 \\
\hline PLA96/2.5C30B & & 43 & 4.2 & 0.86 & 42 & 6.0 & 0.96 & 34 & 0.18 \\
\hline PLA96/0.5C30B & $\mathrm{TD}$ & 15 & 0.6 & 0.72 & 37 & 3.9 & 0.98 & 32 & 0.12 \\
\hline PLA96/2.5C30B & & 31 & 1.7 & 0.56 & 35 & 4.1 & 0.98 & 32 & 0.13 \\
\hline PLA98/0.5C30B & MD & 44 & 1.5 & 0.80 & 37 & 4.8 & 0.991 & 35 & 0.14 \\
\hline PLA98/2.5C30B & & 50 & 3.4 & 0.82 & 38 & 5.8 & 0.991 & 35 & 0.17 \\
\hline PLA98/0.5C30B & $\mathrm{TD}$ & 22 & 0.13 & 0.63 & 34 & 2.9 & 0.991 & 31 & 0.09 \\
\hline PLA98/2.5C30B & & 26 & 0.5 & 0.58 & 36 & 3.1 & 0.99 & 30 & 0.10 \\
\hline
\end{tabular}

The specific EWF $\left(w_{e}\right)$ increases as the clay content, which is commonly attributed to the high stiffness of the MMT clay particles, and the interaction between the polymer matrix and the organomodifier.

Similarly, the nonessential specific work of fracture $\left(\beta w_{p}\right)$ increases with the addition of the clay particles. It has been stated in a previous work[7] that clay particles hinder the plastic flow during the crack propagation that could cause the reduction in the $\beta w_{p}$ term. Nevertheless, in this case the $\beta w_{p}$ term could be increasing as a consequence of the plasticizing effect,[31] which is in concordance with the elongation discussed in the mechanical properties section.

By applying the thermal treatment to the PLA composite films, the self-similarity in the load versus displacement curves as well as the total yield before crack propagation are accomplished at all (Fig. $\underline{6} b$ ); hence, it was possible to apply the EWF method successfully for determining the fracture parameters in the PLA composite films. The results are listed in Table IV.

The free volume caused by applying the thermal treatment to the composite films seems overlapping the reinforcement effect of the highly rigid MMT clay particles because the values of the $w_{e}$ parameter were quite similar.

Because the $w_{e}$ parameter involves the total yield before crack propagation, SEM micrographs from the fracture surfaces corresponding to the PLA composite films in the MD and TD directions were captured (Fig. $\underline{7}$ ). The vertical lines refer the notch front, and the arrows indicate the final thickness after yielding. The thickness reduction $\left(t_{r}\right)$ was calculated using the following expression:

$t_{r}=\frac{\left(t-t_{f}\right)}{t}$ 
where $t$ is the thickness of the composite film and $t_{f}$ is the final thickness, which was measured in the zone where the ligament reaches a constant thickness reduction.

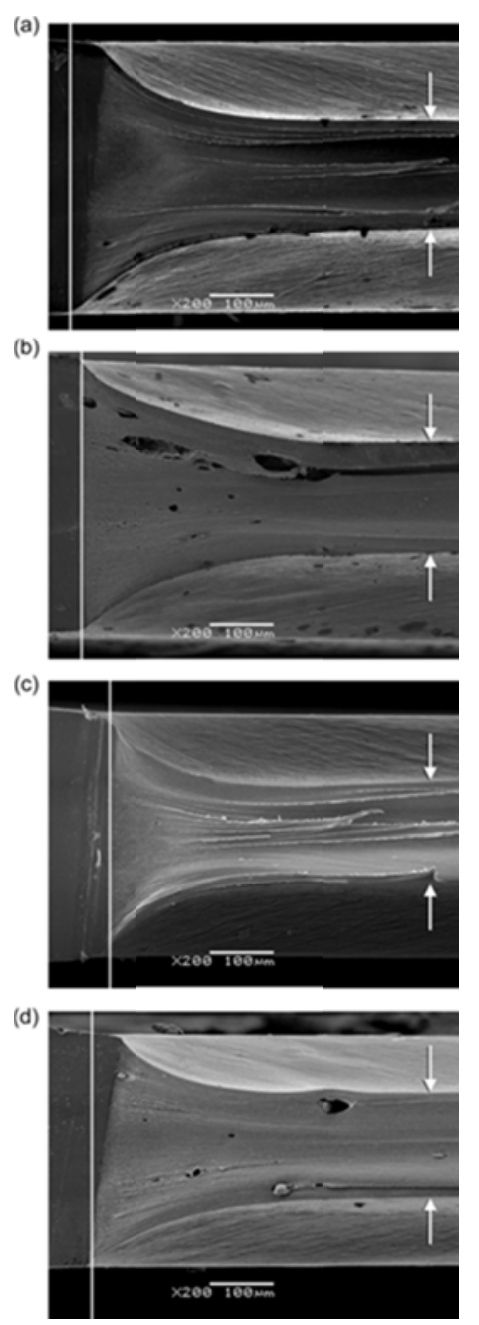

Figure 7.- SEM micrographs corresponding to (a) PLA96/0.5C30B in MD, (b) PLA96/2.5C30B in MD, (c) PLA96/0.5C30B in TD, and (d) PLA96/2.5C30B in TD.

The fracture surfaces revealed the presence of some microvoids, which are commonly representative of PLS because of the decohesion between the polymer matrix and the rigid particles. As expected, the higher the clay content the higher the number of microvoids.

The PLA composite films showed a thickness reduction of $59 \%$ and $60 \%$ in the MD direction (Figs. $7 \mathrm{a}$ and $7 \mathrm{~b}$ ), which is similar to the necking of $57 \%$ and $58 \%$ for drawing the composite films in the TD direction (Fig. $\underline{7 c}$ and $\underline{7 d}$ ). The considerable necking in the ligament section is due to the free volume promoted by the thermal treatment, which promotes that the clay particles do not restrict as much as they can the yielding during the fracture process, even though the clay content increases. Therefore, the smooth variations found in $w_{e}$ should be more related to the chains' orientation in MD than to restriction of the rigid clay particles.

With respect to the plastic term $\left(\beta w_{p}\right)$, it tends to increase with the clay content and is demonstrably higher in MD than TD. $\beta w_{p}$ is considered as a global parameter that takes 
into consideration the whole plastic energy; hence, it can be treated as a measure of the resistance to the crack growth of the material. The calculation of $w_{p}$ (the materialdependent specific energy absorption per unit volume) and $\beta$ (the material-dependent plastic zone shape factor) may be interesting for justifying the tendency of the $\beta w_{p}$ parameter.

To determine $w_{p}$, the method suggested in the European Structural Integrity Society (ESIS) protocol of 1993 was applied.[32] It is worth mentioning that it was possible to adapt the previous methodology only for the thermally treated films because the untreated films did not reveal physically the characteristic whitening on the outer plastic zone (OPZ), as presented in Fig. $\underline{8}$. The OPZ is necessary to know the value of the shape factor.[7]

(a)

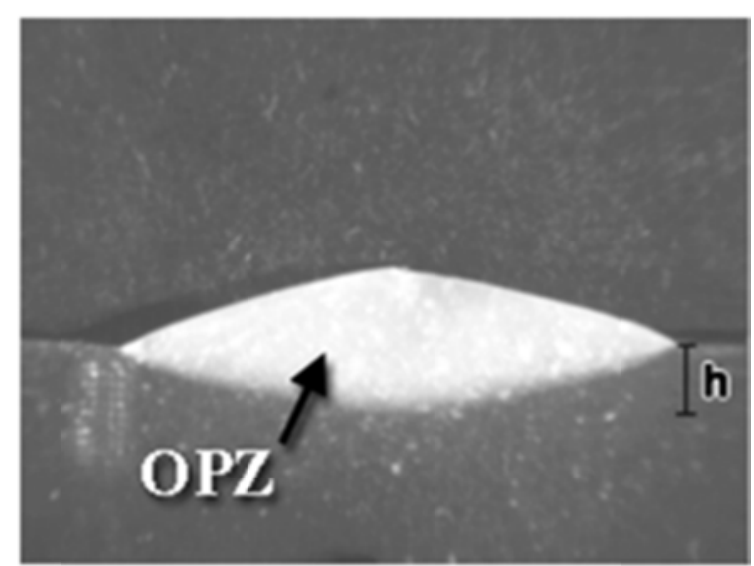

(b)

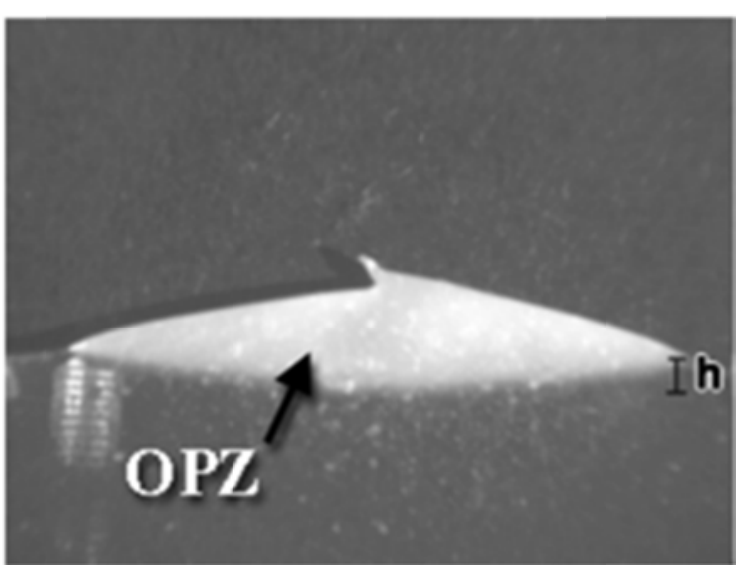

Figure 8.- Micrographs of fractured specimens, where the OPZ developed during the fracture can be seen: (a) PLA96/2.5C30B in MD and (b) PLA96/2.5C30B in TD direction.

In this work, $\beta$ was defined as the intersection of two parabolas and was deduced from the following expression:

$h=\frac{3}{2} \beta \ell$. $(4)$

where $h$ is the total height of the deformed zone and includes the two parts of the broken specimen.[6,7] According to Eq. (4), the linear regression is obtained by plotting $h$ 
versus $\ell$ and $\beta$ is determined from the slope of the straight line. The results are presented in Table IV.

The $w_{p}$ term shows similar values in spite of the increase in the clay content, which is an unexpected behavior because the rigid clay particles limit the work dissipated during the fracture process.[7] Therefore, the results should imply the clay particles do not hinder the plastic flow by applying the thermal treatment.

Smooth variations were found in the specimens tested in the MD direction where $w_{p}$ was slightly higher with respect to the TD direction.

The main differences were related to the shape factor, where the values of $\beta$ increase slightly with the clay content, being more notorious when the PLA composite films are drawing in the MD than the TD direction. It is worth noticeable that the values of $\beta$ measured in this work were very small if they are compared with other works.[7] It has been stated that in PLS the difference in the size of $\beta$ is mainly related to the energy dissipation promoted by the skewed clay particles[7] promoting effective stress transfer. Therefore, the greater the energy dissipation the greater the size of OPZ (Fig. $\underline{8}$ ), and the $\beta$ factor increases as well. In this work, large skewed particles were not developed at all, according to the data obtained from the $\ell_{p \mathrm{TD}} / \ell_{p \mathrm{MD}}$ relationship presented in Table $\underline{\mathrm{II}}$, and the results obtained could be related more to the orientation of the polymer chains in MD than the filler.

\section{Conclusions}

In this work, calendered PLA composite films were successfully prepared using the melt extrusion process. The PLA was shown to be very sensitive to the compounding process, which was mainly associated with temperature and shear stress, which caused the development of tactoids and intercalated structures.

The image analysis was very useful for counting of the number of clay particles, but some problems came up when sizing the filler. Both the $1_{p}$ and $t_{p}$ dimensions were inconclusive because of distorted and poorly aligned particles, which were associated with the poor shearing produced by the low viscosity during melt extrusion.

The influence of the clay particles' morphology on their mechanical properties and fracture behavior was evaluated in the MD and TD directions, finding slight traces of anisotropy caused by the polymer chains orientation that improved the mechanical performance of the films in the MD direction.

The mechanical and fracture results were analyzed using unthermal treated films (aging) and treated films (deaging). For aging composite films, the clay improved the stiffness of the PLA but the tensile strength did not show significant variations. The ductility increased with the clay content because of the plasticizing effect promoted by the organomodifier of the filler.

The $w_{e}$ term increases with the addition of the clay due to the high stiffness nature of the clay and the interaction between the PLA and the organomodifier. The $\beta w_{p}$ increases with the addition of the clay particles as a consequence of the plasticizing effect. 
The free volume caused by applying the thermal treatment to the PLA composite films overlaps the true contribution of the clay particles to the mechanical properties and the fracture parameters to be clarified.

\section{Acknowledgments}

The authors thank the MICINN of Spain for the financing of the MAT2010-19721-C0201 project. J. C. Velazquez-Infante thanks to the AECID for the support in the form of a doctoral research grant.

\section{References}

1Auras, R. Encyclopedia of Polymer Science and Technology; Wiley: Hoboken, NJ, 2002.

2Auras, R.; Harte, B.; Selke, S. Macromol Biosci 2004, 4, 835-864.

3Singh, S.; Ray, S. S. J Nanosci Nanotechnol 2007, 7, 2596-2615.

4Vaia, R. Nature Mater 2005, 4, 429-430.

5Winey, K. I.; Vaia, R. A. MRS Bull 2007, 32, 314-322.

6Franco-Urquiza, E.; Gamez Perez, J.; Sánchez-Soto, M.; Santana, O. O.; Maspoch, M. L. Polym Int 2010, 59, 778-786.

7Maspoch, M. L.; Franco-Urquiza, E.; Gamez-Perez, J.; Santana, O. O., SánchezSoto, M. Polym Int 2009, 58, 648-655.

8Wu, T. M.; Wu, C. Y. Polym Degrad Stab 2006, 91, 7-7.

9Chang, J.-H.; An, Y. U.; Cho, D.; Giannelis, E. P. Polymer 2003, 44, 3715-3720.

10Cui, L.; Paul, D. R. Macromol Symp 2011, 301, 9-15.

11Fornes, T. D.; Yoon, P. J.; Keskkula, H.; Paul, D. R. Polymer 2001, 42, 9929 9940.

12Fornes, T. D.; Paul, D. R. Polymer 2003, 44, 4993-5013.

13Basilissi, L.; Di Silvestro, G.; Farina; H.; Ortenzi; M. A. J Appl Polym Sci 2013, 128, 3057-3063.

14Fukushima, K.; Tabuani, D.; Arena, M.; Gennari, M.; Camino, G. React Function Polymers, 73, 540-549.

15Gorrasi, G.; Milone, C.; Piperopoulos, E.; Lanza, M.; Sorrentino, A. Appl Clay Sci 2013, 71, 49-54. 
16Zaidi, L.; Bruzaud, S.; Bruzaud, S. p.; Kaci, M.; Kaci, M.; Bourmaud, A.; Gautier, N.; Grohens, Y. Polym Degrad Stab 2013, 98, 348-355.

17Hussain, F.; Hojjati, M.; Okamoto, M.; Gorga, R. E. J Compos Mater 2006, 40, $1511-1575$.

18Halpin, J. C. J Compos Mater 1969, 3, 732-734.

19Clutton, E.; D. R. Moore, A. P.; Williams, J. G. European Structural Integrity Society; Elsevier: Amsterdam, 2001; pp. 177-195.

20Cotterell, B.; Reddel, J. K. Int J Fract 1977, 13, 267-277.

21Broberg, K. B. J Mech Phys Solids 1975, 23, 215-237.

22Mai, Y.-W.; Cotterell, B. Int J Fract 1986, 32, 105-125.

23Ferrer-Balas, D.; Maspoch, M. L.; Martinez, A. B.; Santana, O. O. Polymer 2001, 42, 1697-1705.

24Gámez-Pérez, J.; Velazquez-Infante, J. C.; Franco-Urquiza, E.; Pages, P.; Carrasco, F.; Santana; O. O.; Maspoch, M. L. eXPRESS Polym Lett 2011, 5, 82-91.

25Cailloux, J.; Santana, O. O.; Franco-Urquiza, E.; Bou, J. J.; Carrasco, F.; Maspoch, M. L. J Mater Sci 2014, 49, 4093-4107.

26Martínez, A. B.; Segovia, A.; Gamez-Perez, J.; Maspoch, M. L. Eng Fract Mech 2009, 76, 1247-1254.

27Bigg, D. M. Adv Polym Technol 2005, 24, 69-82.

28Alexandre, M.; Dubois, P. Mater Sci Eng, R 2000, 28, 1-63.

29Fornes, T. D.; Yoon, P. J.; Hunter, D. L.; Keskkula, H.; Paul, D. R. Polymer 2002, 43, 5915-5933.

30Saito, T.; Okamoto, M.; Hiroi, R.; Yamamoto, M.; Shiroi, T. Macromol Rapid Commun 2006, 27, 1472-1475.

31Arkhireyeva, A.; Hashemi, S. Polymer 2002, 43, 289-300.

32Gray, R.; ESIS (Ed.): European Structural Integrity Society (ESIS) - TC4, 1993. 
